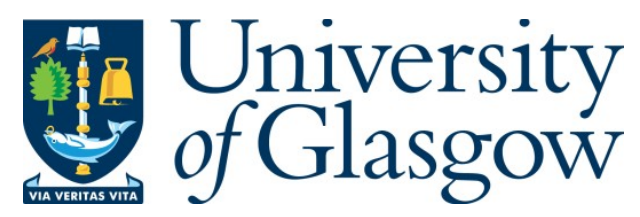

Cowan, R. (2016) Epistemic perceptualism and neo-sentimentalist objections.

Canadian Journal of Philosophy, 46(1), pp. 59-81.

There may be differences between this version and the published version. You are advised to consult the publisher's version if you wish to cite from it.

http://eprints.gla.ac.uk/114183/

Deposited on: 6 January 2017

Enlighten - Research publications by members of the University of Glasgow http://eprints.gla.ac.uk 


\title{
Epistemic Perceptualism and Neo-Sentimentalist Objections
}

\author{
Robert Cowan \\ Philosophy \\ School of Humanities \\ University of Glasgow \\ Scotland \\ G12 8QQ \\ Email: robert.cowan@glasgow.ac.uk
}

\begin{abstract}
Epistemic Perceptualists claim that emotions are sources of immediate defeasible justification for evaluative propositions that can (and do) sometimes ground undefeated immediately justified evaluative beliefs. For example, fear can constitute the justificatory ground for a belief that some object or event is dangerous. Despite its attractiveness, the view is apparently vulnerable to several objections. In this paper I provide a limited defence of Epistemic Perceptualism by responding to a family of objections which all take as a premise a popular and attractive view in value theory - Neo-Sentimentalism - according to which values are analysed in terms of fitting emotions.
\end{abstract}

Keywords: perceptual theory of emotions; immediate justification; affective intuitionism; neo-sentimentalism; evaluative judgment

Acknowledgements: I would like to thank two anonymous referees for this journal for their helpful comments. I also benefited from feedback on a previous version of the paper from an audience at the $23^{\text {rd }}$ Bled Philosophical Conference, as well as valuable discussions on the paper with Jennifer Corns. Thanks also to Michael Milona and Martin Smith for providing very helpful comments on a previous draft. 
Biographical Note: Robert Cowan is a Lecturer in Philosophy at the University of Glasgow. His principal research interests lie at the intersection between ethics, epistemology, and the philosophy of mind. Recent publications include 'Perceptual Intuitionism' (Philosophy and Phenomenological Research, 2015) and ‘Clarifying Ethical Intuitionism’ (European Journal of Philosophy, 2013). 


\section{Introduction}

A currently popular view in the philosophy of emotions is the Perceptual Theory (hereafter 'Perceptualism'; see, e.g., Döring 2003, 2007; Elgin 2008; Roberts 2003; Tappolet 2011, 2012). Put crudely, Perceptualists claim that occurrent and conscious emotions ${ }^{1}$ are, or are best understood by analogy with, perceptual experiences of values, e.g., fear is an experience of danger, guilt an experience of having done something wrong, and so on.

Here are four reasons commonly offered in its favour: emotions, e.g., fear, like experiences, e.g., sensory perception of a red ball, (i) purport to tell us about the world, i.e., they are intentional (this is typically characterised as being representational or presentational - more on this later); (ii) have a phenomenal character, i.e., there's something-it-is-like-for-a-subject to undergo them; ${ }^{2}$ (iii) are phenomena which we are, to some extent, passive in the face of, e.g., 'I was overcome with guilt', or, 'I was struck down with fear'; (iv) are capable of conflicting with beliefs with similar content without outright contradiction, e.g., recalcitrant guilt in the face of a judgment (or knowledge) that I have done nothing wrong doesn't involve my simultaneously judging that $\mathrm{p}$ and not-p.

I'll be more specific about Perceptualism later. This paper is focused on a view about the epistemic properties of emotions that one might adopt if one takes Perceptualism seriously: emotions can (and sometimes do) confer immediate prima facie justification for evaluative beliefs (hereafter 'Epistemic Perceptualism’; see, e.g., Cuneo 2006; Döring 2003, 2007; Pelser 2014). On this view, my guilt can (and sometimes does) provide prima facie justification, sufficient in the absence of defeaters to make it epistemically permissible to believe that, e.g., what I did was wrong, independently of having justification for believing other supporting propositions. Epistemic Perceptualists also hold the view that emotions can 
(and sometimes do) constitute the justificatory basis for undefeated doxastically justified evaluative beliefs. ${ }^{3}$

Although an epistemic premise is required in order to get from Perceptualism to Epistemic Perceptualism (more later), acceptance of the former arguably provides reason for exploring the prospects for the latter, i.e., if emotions are perceptual perhaps they have a perceptual epistemology. Independently of this, the idea that emotions can be revelatory of evaluative features arguably has support in common-sense thinking (and coheres with the claim that emotions are intentional). Guilt can be the way in which we realise the moral import of our actions, while disappointment might reveal to its subject how much something meant to them. In such cases we might think that subjects gained justified evaluative beliefs via their emotion.

Epistemic Perceptualism (hereafter 'EP') is also attractive for at least three reasons. Firstly, it promises a way of halting the epistemic regress for evaluative beliefs, i.e., it identifies a source of evaluative justification that isn't itself in need of justification. This will, however, only be of interest to those who think epistemic justification is linear. The second attraction is broader in scope: EP potentially provides an empiricist-friendly epistemology of evaluative (including moral) knowledge that doesn’t require a weird philosophy of mind, e.g., a special faculty of intuition. Emotions can constitute non-mysterious value data. ${ }^{4}$ Finally, if emotions are motivational states (more on this later), then EP might partially elucidate the putative connection between evaluative judgment and motivation. ${ }^{5}$

Despite the considerations in favour of EP, and its attractiveness, it's apparently vulnerable to various objections. One might raise doubts about the reliability of emotions. ${ }^{6}$ Or one might argue that emotions are epistemically dependent upon other mental items, e.g., beliefs, and hence can't be sources of immediate justification. Or perhaps EP misidentifies the epistemic 
goal of evaluative thought as knowledge when it's actually understanding. In this paper I focus instead on a set of objections that all take as a premise a currently popular and apparently plausible view in the metaphysics/conceptual analysis of value. Specifically, I consider objections that assume Neo-Sentimentalism, according to which some object or event $\mathrm{X}$ has an evaluative property $\mathrm{Y}$ iff an emotional response, $\mathrm{E}$, is a fitting response to $\mathrm{X}$ (see D’Arms and Jacobsen 2000a, 2000b; McDowell 1998; Wiggins, 1998). To illustrate: for Beethoven's Hammerklavier Sonata to possess the property of being admirable is for it to possess the normative property of making fitting admiration. I'll say more about this view, its motivations, and attractions, later.

Given the assumption of Neo-Sentimentalism (hereafter 'NS'), some philosophers (Brady 2013; Goldie 2004) have argued that emotions are epistemically superfluous vis-à-vis evaluative beliefs, since features of objects and events that render an emotion fitting will also render a relevant evaluative belief fitting, independently of the emotion. Also, it might be thought (Deonna \& Teroni 2012; Dokic \& Lemaire 2013; Tappolet 2011) - on phenomenological grounds - that emotions don't have the right sort of content to immediately justify evaluative judgments with NS content. Furthermore, if emotions do have the right sort of content, EP apparently entails that emotions are (or could be) self-justifying (Brady 2013). But emotions are not, and couldn’t be, self-justifying. Hence, we should reject EP.

One could attempt to respond to these objections by denying NS or modifying it such that it's more amenable to EP. Here I adopt a different approach. I argue that EPs can respond to all of these objections, whilst granting NS in its 'standard' form. In doing so I take myself to achieve three things: firstly, to provide a limited defence of EP; second, to highlight some theoretical resources available to EPs in defending their view; third, to establish points which are of general significance for value theory. 
In §2 I outline Perceptualism, EP, and NS. In §3 I respond to two versions of the Superfluity Objection. In §4 I respond to the No Neo-Sentimentalist Content Objection and the SelfJustification Objection. In §5 I conclude.

\section{Perceptualism, Epistemic Perceptualism, and Neo-Sentimentalism}

\subsection{Perceptualism}

Although not wholly uncontroversial, there's a reasonable degree of consensus among contemporary philosophers of emotion that paradigm cases of emotions, e.g., guilt in response to infidelity, implicate the following elements: (i) a representation of some target object or event, e.g., a belief that I have lied to you; (ii) an evaluation or appraisal of that target object or event, e.g., that my lying to you was wrong; (iii) a motivation to act which is intelligible in light of the representation and evaluation, e.g., to apologise or make reparations; (iv) affective phenomenology, e.g., an unpleasant 'yucky' feeling, and, (v) bodily changes (and perhaps an awareness thereof), e.g., lump in throat, sweating. ${ }^{7}$

Substantive disagreement emerges when we theorise about which of these elements are constitutive of emotions, which are mere eliciting causes and effects, and what the nature is of the component parts and their relations.

As stated, Perceptualists think that emotions are, or best understood by analogy with, perceptual experiences of value. I've already outlined reasons in its favour. I'll now be more specific about the view. Perceptualism can be understood as an account of the evaluative element in emotion (component (ii)): it's a perceptual experience, or perceptual-like state with evaluative content. From this point, there are a number of ways in which Perceptualism could be developed. I note here only a few. 
Perceptualists differ regarding their account of the nature of the evaluative element. One set of views claims that it's constituted by the affective element, i.e., the affective phenomenology is the (re)presentational vehicle vis-à-vis emotions' evaluative content (one might also think that the affectivity is motivational). For example, emotions may have a distinctive 'feeling-towards' intentionality which isn't reducible to an awareness of bodily change (see Goldie 2000). If that's right, it might be tempting to think that emotional evaluation has a different sort of content (and perhaps involves a different attitude) to that of evaluative judgments, i.e., it’s non-conceptual (see Döring 2007; Tappolet 2012). ${ }^{8}$ Alternatively, Perceptualists might claim that the perceptual evaluation constitutive of emotions is distinct from the affective and other elements. For example, perhaps the evaluation is a kind of non-doxastic seeming state (see Roberts 2003). On this view, emotions may have similar conceptual content to evaluative judgments, but involve a different sort of non-doxastic attitude towards that content, i.e., its merely seeming to the subject that p rather than being committed to the truth of $\mathrm{p}$.

Both kinds of view need to provide an account of the other elements implicated in emotional scenarios are parts of the emotion. One question concerns whether to count the representation of the target object or event (element (i)) - the “cognitive base” (Deonna and Teroni 2012) as sometimes constituting part of emotion, or, always as an elicitor of the emotion. Call the first kind of view 'Complex', and the second 'Simple'. To illustrate, suppose that I have a fearful experience in response to the perception of a snake. Simple theorists will claim that my perceptual experience is an elicitor of the emotion, while Complex theorists can allow that the perceptual experience of the snake is part of the emotion. Whether Complex theorists can include beliefs as part of an emotion, whilst still being a perceptual theorist, is a further question. $^{9}$

I'll remain ecumenical on these views. The reader is invited to keep them in mind. 


\subsection{Epistemic Perceptualism}

I assume that proponents of EP agree that experiences can (and sometimes do) confer immediate prima facie propositional justification for beliefs. ${ }^{10}$ Firstly, the justification is immediate, i.e., it obtains independently of the subject having justification for believing other propositions. Put another way, the experience is positively epistemically independent of, e.g., beliefs about the reliability of one's perceptual system. Second, the justification is prima facie, in the sense that it can be defeated, e.g., if the subject comes to believe that I am hallucinating. Put another way, the justification is negatively epistemically dependent upon the subject not coming to possess evidence of a particular sort (we should also allow for the possibility of non-evidential defeaters). Thirdly, this is a claim about propositional justification. A subject might have propositional justification for $\mathrm{p}$ without basing a belief that p upon this, in which case their belief might fail to be doxastically justified. However, proponents of EP also claim that emotions are at least sometimes the ground of doxastically justified evaluative beliefs.

EP can take two general forms: Reliabilism and Phenomenalism.

Reliabilist EPs think that a subject, S, has immediate prima facie propositional (perceptual) justification for believing that p iff S has (i) an experience with an appropriate content, e.g., p, and, (ii) the experience is produced by a reliable process. ${ }^{11}$ On this view, an emotion can constitute the evidential ground or basis for an evaluative belief, but does so in virtue of a non-evidential property: the emotion being produced by a reliable process, i.e., one which issues in a favourable ratio of veridical to non-veridical states (for experiences the process is typically assumed to be causal). Reliabilist EPs owe us an account of how emotions could be produced by reliable processes. In what follows I set aside these worries. 
Phenomenalists think that a subject, S, has immediate prima facie propositional (perceptual) justification for believing that $\mathrm{p}$ iff $\mathrm{S}$ has an experience with presentational phenomenal character with respect to p. On this view, emotions can constitute the evidential base for evaluative beliefs in virtue of their phenomenology. 'Presentational' character with respect to p apparently differs substantially from an analogous representational content found in a belief or judgment that p, e.g., compare visually perceiving the red postbox at the end of the road with judging that the postbox at the end of the road is red. ${ }^{12}$

There are roughly two competing accounts of presentational phenomenology: Weak and Robust. On Weak (Bengson 2013), an experience has presentational phenomenology with respect to p just in case it involves its seeming to the subject that p. On Robust (Chudnoff 2013) an experience has presentational phenomenology with respect to p iff it both makes it seem to the subject that $\mathrm{p}$ and makes it seem to them as if the experience makes them aware of a truth-maker for p. Arguably, sensory experiences of colour properties, e.g., redness, are candidates for having Robust presentational phenomenology, while the phenomenology of sensory experiences of 'high-level' properties like being a piece of gold (if there are any) is plausibly only Weak. I'll remain ecumenical about which is required for experiences to confer immediate justification.

How are Perceptualism and EP related? As noted earlier, Perceptualism is insufficient for EP. One might be tempted, however, to think that Perceptualism is necessary for EP. This is especially plausible if one adopts a Phenomenalist epistemological account.

\subsection{Neo-Sentimentalism}

Neo-Sentimentalists characterise evaluative properties and concepts in terms of fitting emotional responses (I'll speak of properties, but a dual view of properties and concepts should be assumed). Roughly, some object or event X has an evaluative property, e.g., 
dangerousness iff an emotional response, e.g., fear, is a fitting response to X. Fittingness is typically understood to be a normative relation, i.e., for the dog to be dangerous, is just for the dog to possess a property or properties that (in some sense) provide reasons for fear. To illustrate: the fact that the dog has snarling teeth and is racing towards me, are reasons for fear; the fact that I have lied to you and broken your trust, are reasons for guilt.

I'm assuming the truth of NS and won't be evaluating it. I here note a couple of its attractions: firstly, it apparently constitutes a 'middle-way' between an objectionable Subjectivism (where evaluative properties are in some way reducible to our actual emotional responses) on the one hand, and a seemingly mysterious Robust Realism (where evaluative properties are entirely independent of human responses) on the other. One way in which this apparently manifests itself regards the connection between evaluative judgment and motivation, i.e., if judging that $\mathrm{X}$ is admirable amounts to judging that admiration is a fitting response to $\mathrm{X}$, then this might partially explain the connection between judgment and motivation posited by Motivational Internalism.

Although I'm assuming NS, proponents have had difficulty in delineating the relevant notion of fittingness without (i) conflating the relevant reasons with the wrong kind of reasons or (ii) resorting to an appeal to the very evaluative properties that they're attempting to provide an account of (e.g., D’Arms \& Jacobsen 2000a, 2000b; Rabinowicz \& Rønnow Rasmussen 2004).

Regarding (i), on some views it's possible for a joke to be funny such that amusement would be a fitting response (in the NS sense), yet because of, e.g., the joke's sectarian content, there are moral reasons not to be amused. Or, there might be prudential reasons to feel ashamed about one's upbringing e.g., because an Evil Demon is threatening to harm your family if you don't, despite shame being unfitting because one's upbringing is nothing to be ashamed of. 
Regarding (ii), this is arguably only a problem for reductive versions of NS which aim to reduce evaluative properties to deontic ones, i.e., reasons for emotions. On other views (McDowell 1987), any such reference to evaluative properties on the right-side of the biconditional is unproblematic, since they claim that there's no-priority between evaluative and deontic properties. The circularity isn't vicious. ${ }^{13}$

Here I assume that there's a viable normative conception of fittingness. Perhaps it's a sui generis emotional normativity. ${ }^{14}$ If NS is true then this entails that emotions are subject to a special kind of normative assessment - (un)fittingness - that sensory experiences are apparently not. This disanalogy has been thought to have important implications for EP as I now discuss.

\section{The Superfluity Objections}

I begin by arguing that emotional fittingness is compatible with EP. Firstly, given NS, one might think that in order to justify evaluative beliefs, emotions must be fitting. One way of cashing this out would be to claim that emotional unfittingness trumps emotions' capacity to confer epistemic justification. However, even if emotional fittingness can override emotions' capacity to confer epistemic justification, this is compatible with the claim that emotions can confer immediate prima facie justification. Emotional unfittingness would simply be a source of (non-evidential?) epistemic defeat for emotions' capacity to confer justification. Negative epistemic dependence upon the absence of defeaters is compatible with immediate justification.

Secondly, even if emotional fittingness were a precondition for emotions' capacity to confer justification this wouldn't undermine EP either. Although an acceptance of this would require an amendment to versions of EP - since emotions can justify evaluative beliefs only if 
they're fitting - it doesn't undermine the claim that when emotions are fitting they can confer immediate justification and ground immediately justified beliefs.

\subsection{Superfluity Objection \#1}

At a basic level, then, NS is compatible with EP. However, it has recently been argued that the assumption of NS leaves EP vulnerable to what I call the 'Superfluity' Objection (Brady 2013; Goldie 2004):

P1: Considerations that constitute reasons for an emotion are also reasons for an evaluative belief with similar content (and vice versa).

P2: If considerations that constitute reasons for an emotion are also reasons for an evaluative belief with similar content (and vice versa) then emotions are epistemically superfluous vis-à-vis the justification of evaluative beliefs.

P3: If emotions are epistemically superfluous vis-à-vis the justification of evaluative beliefs then they don’t confer immediate justification for evaluative beliefs.

C: Emotions don’t confer immediate justification for evaluative beliefs.

P1 assumes that emotions are assessable for fittingness but makes the additional claim that features which constitute reasons for emotions are also reasons for evaluative judgments (so we are no longer assuming an exclusively 'emotional' sense of fittingness). To illustrate this, consider the following remarks:

The fact that the bull in the farmer's field has sharp horns and is advancing rapidly towards me is a good reason for me to be afraid and a good reason for me to judge that the bull is dangerous. Or the fact that Jones keeps changing his story under questioning, refuses to meet his interlocutor's eyes, and stands to gain financially 
from testifying against the defendant are all good reasons for us to feel mistrust towards Jones and judge that he is untrustworthy as a witness for the prosecution. (Brady, 2013: 113)

Lurking behind P2 is, again, the idea that in order to epistemically justify an evaluative belief, they must be fitting. But P2 claims that if an emotion is fitting, then the relevant evaluative belief that it would putatively justify would also be fitting, seemingly independently of the emotion (by being responsive to reasons). Given this, the emotion is epistemically superfluous.

P3 says that if a source of justification is epistemically superfluous with respect to some token belief, then it doesn’t confer justification for that belief. ${ }^{15}$

In response it's hopefully clear that EPs should reject P2. Even if emotions can epistemically justify beliefs only if they're fitting, and even if in such circumstances the relevant evaluative belief would also be fitting, this doesn't entail that emotions are epistemically superfluous. This is because we are dealing with two distinct forms of assessment. The first is the upshot of NS (emotions/evaluative beliefs are fitting iff they are responding to reasons), while the other is a distinctive epistemic sense of justification (emotions can confer epistemic justification iff they have, e.g., presentational phenomenology). An evaluative belief might be epistemically unjustified in the absence of emotion, despite being fitting, e.g., the evaluative belief might have been unreliably formed.

Admittedly, emotions would seem to be epistemically superfluous if it were true that whenever emotions could confer epistemic justification for evaluative beliefs, the relevant evaluative belief was epistemically justified independently of the emotion. But nothing in the present form of the Superfluity Objection establishes this. 


\subsection{Superfluity Objection \#2}

My response to the Superfluity Objection is complicated by the fact that emotions are apparently “always grounded in...cognitive bases” (Deonna and Teroni 2012: 5) e.g., a belief that I have lied to you. Recall that on Simple this renders emotions as mediated states. Complex theorists claim that 'cognitive bases' can be part of the emotion.

In light of this, it might be thought that just as there can be false but epistemically justified beliefs, there can be emotions which are unfitting (they're not as a matter of fact responding to reasons) but rational because their cognitive bases are such that if their content were true/veridical, the emotion would be fitting (Parfit 2001). For example, my fear might be rational because its cognitive base is a belief that there's a tiger about to attack me (a content which, if true, would make fear fitting), despite this belief being false. Call this 'Rational Fittingness'.

Is the assessability of emotions for rational fittingness compatible with EP? Claiming that rational (un)fittingness is a defeater or precondition for emotions' capacity to confer epistemic justification is compatible with EP (although note again that preconditionality requires modifications to EP). This is because all that's required for rational fittingness is that the cognitive base of the emotion has a particular sort of content (Parfit 2001), i.e., one that would - if true or veridical - make the emotion fitting. It isn’t required that the cognitive bases be epistemically justified or justification-conferring, e.g., if I unjustifiably believe that my dog has demonic powers and is intent on my destruction, this would make fear towards it rationally fitting, despite the belief being epistemically unjustified.

Suppose, however, that the cognitive bases did need to be justified or justification-conferring in order for the relevant emotion to be capable of conferring epistemic justification, i.e., those states being justified or justification-conferring is a precondition for rational fittingness. 
Would this undermine EP? No. Even if emotions are rationally fitting only if their cognitive bases are justified or justification-conferring (in addition to having the right content) this could still be compatible with their functioning as 'value data', and serving as generative sources of justification for evaluative beliefs. Put another way, emotions could be epistemically dependent upon their cognitive bases whilst being fundamental sources of evaluative justification ${ }^{16}$ (I assume that emotions aren't, strictly-speaking epistemically dependent. They're dependent upon cognitive bases being justified/justification-conferring in order for them to be rationally-fitting and hence capable of conferring epistemic justification. However, one might say this is de facto epistemic dependence).

To clarify: on the current proposal, an emotion, e.g., guilt, would fail to justify an evaluative belief, e.g., my having lied to you was wrong, if its cognitive base, e.g., a belief that I have lied to you, was itself unjustified (and had an appropriate content vis-à-vis emotional fittingness). This is the sense in which it's (de facto) epistemically dependent. However, when the cognitive base of an emotion is justified, emotions can justify beliefs with evaluative content independently of having further justification for believing evaluative propositions, i.e., emotions remove the need for an evaluative premise linking the presence of properties given to us by the cognitive bases with the presence of an evaluative property. This is the sense in which emotions are epistemically fundamental. If this picture is right, then emotions being epistemically dependent upon their cognitive bases is compatible with their playing the epistemic role that EPs require of them.

This combination of dependence and fundamentality might seem odd. It isn't, however, without precedent: it would mirror the ontological relation that apparently holds between emergent properties and their base properties, e.g., between mental states and physical states/processes of the brain. On this view, mental phenomena are ontologically dependent on physical states/processes, but are nonetheless ontologically fundamental (see Barnes 2012). 
Hence, one way of understanding the current proposal about emotional justification, is that emotions constitute emergent sources of justification for evaluative propositions.

I've suggested that emotions' assessability for rational fittingness is compatible with EP, i.e., even if rational unfittingness is a defeater or a precondition for emotions' capacity to confer epistemic justification, this is compatible with their playing a fundamental epistemic role visà-vis evaluative propositions. However, an opponent of EP may demur. Specifically, they might pose the 'Superfluity Objection \#2': ${ }^{17}$

P1: Considerations that constitute reasons for an emotion are also reasons for an evaluative belief with similar content (and vice versa).

P2: In order to be rationally fitting, an emotion must be based upon an identification of the considerations that are reasons for the emotion as having the status as reasons.

P3: If P2 is true, then emotions are epistemically superfluous vis-à-vis the relevant evaluative belief.

P4: If emotions are epistemically superfluous vis-à-vis the relevant evaluative belief, then they don't confer generative justification for the evaluative belief.

C: Emotions don’t confer generative justification for evaluative beliefs.

P1 has been explained. P2 claims that it's insufficient for rational fittingness that emotions have non-evaluative cognitive bases (which if true/veridical would make the emotion fitting). Instead, emotions must be based upon a prior identification of the considerations that are reasons as reasons. What might this involve? Perhaps it's a value intuition, a sensory experience of reasons (Church 2010), ${ }^{18}$ or a cognition based upon reflection and experience (Brady 2013). 
P3 assumes that in order to be capable of justifying evaluative beliefs, emotions must themselves be fitting (it's a precondition). This requires - according to P2 - that they have a base which identifies the reasons as reasons. However, it's plausible that such an identification of reasons as reasons would itself need to be justified or justification-conferring in order for the emotion to be fitting. If an emotion is based upon states with normative or evaluative content, e.g., my dog's having Demonic power and being bent on my destruction are reasons for fear, it's plausibly insufficient for the rational fittingness of the emotion that the base has a content which if true/veridical would make the emotion fitting. If it were sufficient then all such emotions would be trivially fitting, no matter how bizarre their cognitive base, e.g., the belief that my having dog's having demonic power and being on my destruction are reasons for admiration could - counterintuitively - make admiration rationally fitting (see Parfit 2001).

Instead, it's plausible that cognitive bases with normative content must not be false/falsidical or unjustified/fail to confer justification (perhaps these are necessary conditions). If that's right, however, then whenever an emotion is rationally fitting, one will have a sufficient epistemic justification for the relevant evaluative belief - e.g., an intuitional identification of reasons as reasons - thus rendering the emotion epistemically otiose.

P4 claims that if the emotion is epistemically otiose then it cannot confer generative justification. Recall the discussion of epistemic emergence: there it was claimed that emotions may be able to play an epistemically generative role vis-à-vis evaluative beliefs even if they're not immediate sources of justification. P4 takes that point on board.

This is more troubling than Superfluity Objection \#1 inasmuch as it doesn't commit an equivocation between normative standards: fittingness and epistemic justification. 
In response EPs might try to be concessive by granting P1-P3, but denying P4, i.e., grant that emotions are epistemically superfluous vis-à-vis the relevant evaluative beliefs but deny this entails that emotions cannot confer epistemic justification. On a natural understanding of 'superfluity' this means that token emotions aren’t required for token evaluative beliefs to be epistemically justified. But that's compatible with the relevant token emotions conferring justification for the relevant beliefs. The evaluative belief may be justificatorily overdetermined. Further, if subjects based their evaluative beliefs upon the emotion then, so long as the relevant emotion had the relevant epistemic properties, e.g., reliability, the emotion would ground doxastically justified evaluative beliefs.

However, there's a problem: although the emotion might be capable of conferring justification for the evaluative belief, it mightn't be capable of conferring generative justification. This is because - given the assumption of P2 and P3 - the emotion would be capable of conferring epistemic justification for the relevant evaluative belief only if fitting, which in turn apparently requires that they have a cognitive base which itself provides epistemic justification for believing evaluative or normative propositions, e.g., my dog's having Demonic power and being bent on my destruction are reasons for fear. This would appear to entail that emotions are not generative sources of evaluative justification after-all (although recall that there's only de facto epistemic dependence).

Given this, EPs should reject P2. Firstly, they could claim that it's ad hoc to insist that a requirement for rational fittingness is that emotions are based upon a prior identification of considerations as having the relevant normative/evaluative status. Why, EPs might ask, can’t an emotion be rationally fitting simply by being a response to a non-evaluative base whose content is such that, if true, would render the emotion fitting? The thought would be that these are alternative sufficient conditions for emotional rational-fittingness, but that neither is necessary. 
If the objector insists that it's essential for emotional rational fittingness that there's an identification of the evaluative or normative import of objects, events, or properties, then EPs should deny that this must always involve a prior identification by some non-emotional source. Indeed, one might think that it's question-begging against EP to suggest otherwise. The natural way of interpreting EP is that emotions are sometimes the way in which we nonderivatively come to realise the evaluative/normative import of some object or event. To insist that this is never the case and that emotions must always rely upon some other source of evaluative input seems like a denial of the view. P2 is therefore, at best, dialectically suspicious.

EPs could bolster this by casting doubt on the credentials of the supposed alternative identifications required by P2.

One strategy would be to show that the alternatives aren’t really alternatives. To illustrate: on some views the relevant sorts of evaluative or normative intuitions actually turn out to be emotional experiences, e.g., Dancy’s (2014) view that some intuitions are practical seemings which are kinds of emotions. ${ }^{19}$ Hence, the intuitional view mightn’t actually constitute a competitor to EP. Further, Brady’s (2013: 148) comments about experience and reflection, e.g., as a general capacity to identify reasons, make it sound similar to Dancy's 'practical seemings', which are themselves emotional. Finally, it's plausible that high-level sensory experiences of values may themselves be facilitated by emotion via a process of cognitive penetration. Roughly, cognitive penetration involves a cognitive state, e.g., a belief or emotion, causally impacting on the content of an experience - e.g., by the addition of content - in a way that doesn't merely involve shifts in the subject's attention (see, e.g., Vance 2014). Some (Werner, forthcoming) have argued that emotions may sometimes cognitively penetrate experience to produce evaluative sensory experiences. In such cases, emotions would - in a sense - constitute the 'cognitive base' of sensory experience, not the other way round. ${ }^{20}$ 
Another way of putting pressure on alternative models would be to identify cases where subjects experience an emotion and have a seemingly justified evaluative belief, but where alternative candidate sources aren't plausible cognitive bases for the emotion. Consider the following case:

Bad Budget. John tells Lucy about the details of the recently announced Conservative Government Budget. In response to hearing about how there will be cuts to welfare payments but cuts in inheritance tax, Lucy feels a sense of indignation and judges that the Budget is unjust.

In this case the subject has an emotion and (let's assume) a justified moral judgment. Hopefully it's clear that sensory experience of reasons isn't a good candidate for an evaluative cognitive base for the emotion. ${ }^{21}$ What about a value intuition (and assuming the falsity of Dancy's view)? Although I cannot rule this out, it's worth highlighting that on some contemporary views of intuitions (Chudnoff 2013), they have an abstract subject matter. Hence, intuitions mightn’t take particular cases as their objects.

One might object that we have intuitions in response to particular scenarios in thoughtexperiments, e.g., trolley cases. In response: in thought-experiments there's a sense in which one's response doesn't take a particular case as an object, but rather a type of case, e.g., pushing a person off a bridge (Kagan 2001). If that's right, then although intuitions might sometimes be the cognitive base of emotions in response to thought-experiments, they mightn't ground judgments in response to concrete cases, like Bad Budget. Together with the first point against sensory experience, emotions emerge as strong candidates for generators of evaluative justification in these cases.

One might respond that intuitions could still justify evaluative beliefs about concrete cases via an inference from type to token. However, the claim that an inference takes place in these 
cases mightn’t be plausible on phenomenological grounds. However, this phenomenological claim is highly controversial, e.g., some inferences can surely be unconscious. An alternative way of arguing is to appeal to an epistemological premise: in Bad Budget one doesn't require justification for belief about the type of case in order to have a justified belief concerning the token. ${ }^{22}$ But on the intuition model, this is required. Therefore, we have some reason to reject the intuition model.

Against this, one might adopt Chudnoff's (forthcoming) conception of 'low-level' intuitions. These apparently involve an awareness of an abstract general truth about action types, e.g., lying is prima facie wrong, and also that the general truth applies in the concrete case, e.g., I shouldn't have lied to my partner - that would allegedly avoid the need to posit an inference. Although this might seem to avoid the epistemological argument in the previous paragraph (although that isn’t wholly obvious), this proposal seems vulnerable to a phenomenological objection. On Chudnoff's model of 'low-level' intuitions it seems plausible that one needs to be consciously aware of the general truth. However, it can then be objected that in Bad Budget one needn't be aware of anything general at all.

Admittedly, these remarks are insufficient to undermine alternative accounts. EPs therefore have a theoretical "I Owe You” that they'll need to make good on. My discussion should be understood as amounting to the claim that the prospects for doing so are optimistic. In any case, recall that P2 of the Superfluity Objection \#2 seems to beg-the-question against EP.

If all else fails, EPs might deny P3 and the associated claim that rational fittingness is a precondition for emotions to confer epistemic justification. Instead, rational unfittingness may only be a defeater. If that were true, then in cases where emotions are based upon epistemically good evaluative/normative cognitive bases, they could constitute epistemically 
generative sources of evaluative justification since their capacity to do so would only negatively depend upon the absence of an unjustified cognitive base.

In conclusion: EP is compatible with emotions being assessable for rational fittingness, and can be plausibly defended against the Superfluity Objection \#2. ${ }^{23}$

\section{Neo-Sentimentalist Content and Epistemic Perceptualism}

I now consider objections to EP which assume the truth of NS but also claim that, given this assumption, emotions would need to possess NS content in order for emotions to generatively justify evaluative beliefs. What I'm calling the 'No Neo-Sentimentalist Content' Objection claims that emotions lack NS content, while what I call the 'Self-Justification' Objection grants this but claims that it leads to implausible epistemic consequences. I respond to these in turn, as well as relating the claim that emotions have NS content to the versions of EP.

\subsection{No Neo-Sentimentalist Content Objection}

The No Neo-Sentimentalist Content Objection goes as follows:

P1: Neo-Sentimentalism is true.

P2: Given P1, if emotions can (and sometimes do) immediately justify evaluative beliefs, then they must (at least sometimes) have NS content.

P3: Emotions don’t have NS content.

C: Emotions cannot (and don't) immediately justify evaluative beliefs.

I’ve already explained P1. Recall that I'm granting it.

P2 is apparently plausible because if we grant NS about concepts then evaluative judgments will supposedly deploy concepts of fitting emotions. Hence, in order to justify such 
judgments, emotions must possess an appropriate content: this must be NS content. So, an experience of fear towards some object or event $\mathrm{X}$ must have the content [fear in response to $X$ is fitting]; an experience of guilt must have the content [guilt in response to $X$ is fitting]. The most natural way to understand this content is, I think, in terms of types of emotional responses, i.e., [fear - the type of emotion - is fitting]. However, a proponent of EP might claim that emotions only make us aware of the fittingness of one's token emotion (this fear is fitting), but that this can put one in a position to judge that fear (the type) is fitting.

P3 is a phenomenological claim. The thought is that if emotions did have NS content then they would have a self-referential phenomenology. But they don't: "When we undergo emotions, we seem to be entirely directed outwards to the world and its properties, and in no way 'inwards' to responses that would be appropriate in the circumstances” (Deonna and Teroni 2012: 101). ${ }^{24}$

In emotion we are focused on external objects and events, not the normative status of our emotion (token or type). Note that P3 is only really plausible if one takes emotional phenomenology to be a guide to content. It may pose a particular difficulty for Perceptualist (and EP) views which take the phenomenology to be the (re)presentational vehicle in emotion.

I suggest three ways in which EPs can respond. The first involves denying P2 by adapting a point from Broad (1945). He notes that just because some proposed analysis is true of a particular concept, that doesn't entail that when subjects form attitudes which employ this concept, e.g., beliefs, that they're to be credited with states with the content proposed by the analysis. Broad says:

It is quite obvious that a number of persons who accept different and incompatible analyses of a proposition may all believe it; and therefore there must be a sense in 
which some at least of them believe it without ipso facto believing the proposition which is its correct analysis. (1945: 164)

To illustrate: there's much debate about what the correct analysis of KNOWLEDGE consists in, and indeed whether any such analysis is possible. Suppose for the sake of example that Nozick's Tracking-Theory is correct. There's a sense in which people (including philosophers!) can form judgments about whether some $\mathrm{S}$ knows that $\mathrm{p}$ without being credited with the belief that S's belief is counterfactually sensitive to the truth of $p$. Another way of making this point involves appealing to something like Smith's (1994) model of conceptual analysis: subjects who possess a concept, C, need only satisfy a set of application conditions for the concept in order to be credited with possession. They needn't be in a state of believing the correct analysis when they form beliefs which deploy the concept.

The current proposal is that we say the same about the content of evaluative judgments. Even if the correct analysis of the concept DANGEROUSNESS is that a fearful response would be fitting, that doesn't entail that when subjects judge that something is dangerous they're in a state with this content. This would remove the motivation for thinking that emotions must have NS content.

Note, however, that this sort of response mightn't be available to a Robust Phenomenalist who thinks that an experience justifies only if it has presentational phenomenology, and, an experience has presentational phenomenology with respect to p iff it both makes it seem to the subject that $\mathrm{p}$ and makes it seem to them as if the experience makes them aware of a truth-maker for p. On this view, perhaps emotions require NS content in order to be capable of generatively justifying evaluative beliefs.

This leads to the second response: deny P3. Although some complain that they cannot locate a sort of self-referentialist emotional phenomenology, others disagree: 
We often experience an object, person, or action that we value (or disvalue) as exerting a certain affective pull, an attraction (or repulsion), on us which seems noncontingently connected with the way the object (etc.) itself is. Our affective response in these cases is itself experienced as not merely contingently caused, but as merited by the object's intrinsic character. To say that it is experienced as merited and not merely as caused is to say that its specification constitutively involves reference to the object - it is experienced as the appropriate or right response to some feature of the object, as a registering of the object's nature. For example, people often experience their love for the character of a person, or their aesthetic admiration for a work of art, to be merited by - to be itself an appropriate recognition or registering of - the nature of their object. (Poellner, 2007: 235)

In my own experience (and those with whom I've discussed these matters), I think it plausible that some emotions could have NS content. For example, in experiencing indignation towards the latest Government Budget, there’s a sense in which my experience presents itself as a fitting response to the budget. Similarly, when I contemplate pictures of Pluto taken by the New Horizons space probe, I experience awe at the awesomeness of the universe. In doing so it also seems to me that my experience presents itself as fitting with the nature of the object of my reflection. ${ }^{25}$

These phenomenological points can, perhaps, be given support by considering that emotions allegedly lack the transparency apparently found in sensory experience (Salmela 2011). If you try to describe your sensory experience of, e.g., a red ball, apparently you find yourself simply describing the object and its properties (we see straight through to the objects and properties). However, when we try to describe our emotions we can end up referring, at least partly, to the experience itself, rather than external objects. My suggestion is that emotions' opacity may be thought to fit well with the suggestion that emotions possess NS content, i.e., 
if some emotions have NS content then it wouldn't be surprising that subjects refer, at least partly, to the emotion itself.

Note that the current proposal is that emotions can have NS content. It is doubtful, however, that the emotions of children possess such content. Further, some cases of adult emotions plausibly lack this sense of fittingness, e.g., a case where jealousy transforms into rage. However, all that's required in order to deny P3 is that emotions sometimes have this content.

If one isn't impressed by this response - perhaps there's some in principle reason that disbars emotions from having NS content - EPs can adopt a different kind of denial of P2. Very briefly, this involves claiming that although emotions lack NS content - perhaps they simply represent values, or, perhaps they have non-conceptual content - they can nevertheless play an important epistemic role in generating evaluative judgments which do.

I discuss two versions. Firstly, perhaps emotions sometimes produce seeming states ('affective seemings') with NS content, even if emotions themselves don't. Consider a sensory analogy: perhaps visual experience doesn’t represent sophisticated properties like being a pine tree but nevertheless can cause the occurrence of perceptual seemings that do have this content. Concerning emotions, perhaps emotions don’t possess NS content but can cause and indeed rationalise affective seemings with NS content, which in turn justify evaluative judgments.

Against this, an objector might complain that they can't find seemings in their phenomenology. Further, perhaps positing seemings with NS content is no more phenomenologically plausible than positing this content for emotions themselves.

The second version isn't vulnerable to this. This involves claiming that although emotions don't have NS content, forming judgments with this content on the basis of emotion is a 
reliable process. This would be similar to the claim that some philosophers of perception make regarding immediate perceptual judgments about high-level properties like being a pine tree: although high-level properties don’t get represented in perceptual experience, forming beliefs with that content on the basis of certain kinds of experience is a reliable process. The current proposal is that forming judgments with NS content on the basis of emotions is a reliable process even if NS content doesn't show up in the emotion itself.

In summary: there are several plausible ways in which EPs can respond to the No NS Content Objection. Before considering the Self-Justification Objection I briefly relate the claim that emotions have NS content to versions of EP.

\subsection{Neo-Sentimentalist Content and Epistemic Perceptualism}

If, e.g., guilt, has NS content that [there are reasons to feel guilty towards X], Reliabilist EPs don't appear to face any specific problems. If emotions have this content and are produced by a reliable process (which I'm granting) then they could immediately justify evaluative beliefs. Further, they don't seem to be at a disadvantage vis-à-vis Robust Realism.

Things are more complicated for Phenomenalism. On that view, emotions must possess presentational phenomenology with respect to NS content, e.g., they must present subjects with the content [there are reasons for being afraid of $\mathrm{X}$ ].

Suppose that we require Weak presentational phenomenology, i.e., it seems that p. It's hard to discern principled reasons for rejecting the claim that emotions could have presentational phenomenology of that sort with respect to NS content (given the assumption that emotions have NS content). I think this point holds irrespective of whether we adopt a Simple or Complex view. 
If, however, we require Robust presentational phenomenology - it both makes it seem to the subject that $\mathrm{p}$ and makes it seem to them as if the experience makes them aware of a truthmaker for $\mathrm{p}$ - things are more complicated. To illustrate consider the following case:

Guilty Party. During a conversation with some colleagues at a work Christmas party Alex reveals some intimate details about his partner to them. Alex knows that his partner would be horrified to learn that strangers knew about such private details. After the conversation ends, Alex is overcome with guilt.

Suppose that Alex's guilt has NS content, i.e., [there are reasons for guilt - perhaps only the token experience - towards X]. How could Alex's emotion have Robust presentational content with respect to this content? One way in which it could is if the guilt made Alex aware of the features that constitute reasons for guilt as reasons for guilt. Note that this would be a stronger sort of awareness from cases where one had an experience with content e.g., [there are reasons for guilt towards X], and an awareness of features that constitute such reasons, but without an experience of those features as reasons. Someone who endorses Robust might insist that the (former) stronger sort of awareness is required for presentational phenomenology with respect to NS content. If emotions lack this then they can't immediately justify evaluative beliefs.

Could emotions have this sort of strong awareness? On a Complex view they could. On this picture, Alex's guilt would involve a non-emotional representation of the features that constitute reasons for his guilt (e.g., his having broken trust) and an evaluation [there are reasons for guilt towards $\mathrm{X}]$ directed towards and identificatory of those features, such that the emotion as a whole has the content [my having broken trust is a reason for guilt].

Things are less clear on Simple. If an emotion in Guilty Party could have the content [my having broken trust is a reason for guilt] then there may be a sense in which the emotion has 
presentational phenomenology, even if the representation of one's having broken trust is not itself part of the emotion. Admittedly, this is unobvious.

However, this assumes Robust which EP Phenomenalists might reject. Even if Robust were correct, perhaps experiences with Weak presentational phenomenology could confer some degree of immediate justification, albeit not enough to make belief epistemically permissible. One interesting feature of this proposal is that emotions could still be capable of halting the epistemic regress - by constituting epistemically independent justification - and could still constitute ‘value data’, albeit of a ‘weak’ variety (see Van Roojen 2014).

\subsection{The Self-Justification Objection}

If emotions do possess NS Content, they apparently face the Self-Justification Objection (Brady 2013):

P1: Emotions have Neo Sentimentalist content.

P2: Given P1, if emotions could confer immediate justification for evaluative beliefs then they could confer justification for themselves.

P3: Emotions cannot confer justification for themselves.

C: Emotions cannot confer immediate justification for evaluative beliefs.

P1 has been explained. P2 says that given the supposition of P1 and EP, emotions would justify beliefs with the content [fear towards $X$ is fitting]. P3 claims this sort of 'selfjustification' is dubious.

Against this, EPs should deny P3. They should claim that there's nothing particularly problematic about the claim that emotions can defeasibly justify beliefs about their own fittingness (recall again that the sense in which emotions can justify beliefs about their own 
fittingness is either that they - the token experience - are fitting or that they - the type of experience - are fitting. I'm inclined to think that the former is the more plausible).

EPs can bolster this by pointing out that if sensory experiences can immediately justify beliefs, then subjects can come to have justified beliefs about their accuracy. For example, if I have a justification-conferring sensory experience of a green ball, then I can have immediate justification for believing that there's a green ball, and immediate justification for believing that I'm having an experience of a green ball. From this it seems that I can have (mediate?) justification for believing that my experience is accurate. Although accuracy and emotional fittingness are apparently not identical (although see Tappolet 2011), and although the justification for beliefs about accuracy in the emotional case is immediate rather than mediate, it isn't obvious that these differences create a particular difficulty for EP.

As is well known, the claim that sensory experiences can justify beliefs about their accuracy leads to easy knowledge (Cohen 2002) and bootstrapping (Vogel 2008) worries. Regarding easy knowledge, the worry is that if I can have a justification for believing that my experience is accurate simply on the basis of experience, then I can have justification for anti-sceptical propositions, e.g., I'm not a brain-in-a-vat. But, the objection goes, this is too easy. The bootstrapping worry goes as follows: if I can get justification for believing that my experience is accurate, then, over time, this could enable subjects to justify beliefs about the reliability of sensory experience, i.e., this experience was accurate... this experience was accurate, etc., therefore, my experiences are reliable'. But that's illegitimate bootstrapping.

One might interpret P3 as alluding to something like these sorts of worries for emotions (only regarding fittingness, e.g., if I have justification for believing that my emotion is fitting, then I could deduce anti-sceptical propositions). However, insofar as this is a problem, it isn't a unique problem for EP, but for any view that allows that experiences can immediately justify. 
The Self-Justification Objection therefore threatens to prove too much. Indeed, as should hopefully be clear from these remarks, the Self-Justification Objection could be brought against any version of EP, not only those that assume emotions have NS content, i.e., if NS is true, then one could deduce that one's emotion was fitting even if the emotion didn't have NS content but, e.g., represented values instead.

One might object that there's a unique problem for EP because emotions are epistemically reason-responsive, i.e., are states for which evidence can be given, just like beliefs. Note that epistemic reason-responsiveness neither entails nor is entailed by NS. Although I don't have space to adequately address this, let me say this: it's plausible that, if emotions are indeed epistemically reason-responsive, they could only preserve their own justification (i.e. justification for emotionally (re)presenting the relevant content), even if they can generate justification for beliefs. It may be a constitutive feature of a mental item's being a generator of justification that it can't generate justification for itself.

\section{Conclusion}

I've argued that EP can survive NS-based objections. This should interest those working in value theory and are interested in the interconnections between value epistemology and metaphysics. I've also demonstrated some of the theoretical resources available to EPs, e.g., epistemic emergence. Finally, I’ve provided a limited defence of Epistemic Perceptualism against a series of important objections. Whether the view can survive other objections is a job for another paper.

\section{References}

Bain, D. 2013. “What Makes Pains Unpleasant?” Philosophical Studies 166 (1):69-89. 
Barnes, E. 2012. “Emergence and Fundamentality.” Mind 121 (484):873-901.

Bengson, J. 2015. “Review of Elijah Chudnoff's Intuition.” Notre Dame Philosophical Reviews

Brady, M. 2013. Emotional Insight. Oxford University Press.

Broad, C.D. 1945. "Some Reflections on Moral Sense Theories in Ethics.” Proceedings of the Aristotelian Society.

Chudnoff, E., 2013. Intuition. Oxford University Press.

Chudnoff, E. Forthcoming. "Moral Perception: High-Level Perception or Low-Level Intuition?” In Phenomenology of Thinking, edited by Breyer, T. and Gutland, C. Routledge.

Church, J. 2010. “Seeing Reasons.” Philosophy and Phenomenological Research 80 (3):638670 .

Cuneo, T. 2006. "Signs of Value: Reid on the Evidential Role of Feelings in Moral Judgement.” British Journal for the History of Philosophy 14 (1):69 - 91.

Dancy, J. 2014. “Intuition and Emotion.” Ethics 124 (4):787-812.

D’Arms, J., and Jacobsen, D. 2000a. “Sentiment and Value.” Ethics 110 (4):722-748.

D’Arms, J., and Jacobsen, D. 2000b. “The Moralistic Fallacy: On The 'Appropriateness' of Emotions.” Philosophy and Phenomenological Research 61: 65-90.

Deonna, J. and Teroni, F. 2012. The Emotions: A Philosophical Introduction, Routledge.

Dokic, J. and Lemaire, S. 2013. “Are Emotions Perceptions of Value?” Canadian Journal of Philosophy 43 (2): 227-247.

Döring, S. 2003. “Explaining Action by Emotion.” Philosophical Quarterly 53 (211):214230.

Döring, S. 2007 "Seeing What to Do: Affective Perception and Rational Motivation.” Dialectica 61 (3):363-394;

Elgin, C.Z. 2008. "Emotion and Understanding.” In Epistemology and Emotions, edited by Georg Brun, Uvli Dogouglu and Dominique Kunzle, 33-50. London: Ashgate.

Goldie, P. 2000. The Emotions: A Philosophical Exploration, Oxford University Press.

Goldie, P. 2004. “Emotion, Reason, and Virtue.” In Emotion, Evolution, and Rationality, edited by Evans, D. and Cruse, P., 249—267. Oxford University Press.

Kagan, S. 2001. “Thinking About Cases.” Social Philosophy and Policy 18 (2). 
Kauppinen, A. 2013. "A Humean Theory of Moral Intuition." Canadian Journal of Philosophy 43 (3):360-381.

Lyons, J.C. 2009. Perception and Basic Beliefs: Zombies, Modules, and the Problem of the External World. Oxford University Press.

McDowell, J. 1998. Mind, Value, and Reality. Harvard.

Oddie, G. 2005. Value, Reality, and Desire. Oxford University Press.

Parfit, D. 2001. "Rationality and Reasons”. In Exploring Practical Philosophy: From Action to Values, edited by Egonsson, D., Josefsson, J. Petersson, B. \& Rønnow Rasmussen, T., 1740. Aldershot: Ashgate.

Pelser, A.C., 2014. "Emotion, Evaluative Perception, and Epistemic Justification.” In Emotion and Value, edited by Roeser, S., and Todd, C., 107-23. Oxford University Press.

Poellner, P. 2007. “Affect, Value, and Objectivity.” In Nietzsche and Morality, edited by Leiter, B and Sinhababu, N., 227-61. Oxford University Press.

Prinz, J. 2004. Gut Reactions: A Perceptual Theory of the Emotions. Oxford University Press.

Pryor, J., 2005. “There is Immediate Justification.” In Contemporary Debates in Epistemology, edited by Steup, M. and Sosa, E., 181-202. Blackwell.

Rabinowicz, W. and Rønnow Rasmussen, T. 2004. "The Strike of the Demon: On Fitting Pro-Attitudes and Value.” Ethics 114 (3):391-423.

Roberts, R.C. 2003. Emotions: An Essay in Aid of Moral Psychology, Cambridge University Press.

Salmela, M. 2011. “Can Emotion Be Modelled On Perception?” Dialectica 65 (1):1-29.

Scanlon, T. 1998. What We Owe To Each Other. Harvard.

Smith, M. 1994. The Moral Problem. Blackwell.

Tappolet, C. 2000. Emotions et Valeurs, Paris: Presses Universitaires de France.

Tappolet, C. 2011. “Values and Emotions: Neo-Sentimentalism’s Prospects.” In Morality and the Emotions, edited by Bagnoli, C., 117-134. Oxford University Press.

Tappolet, C. 2012. "Emotions, Perceptions, and Emotional Illusions." In Perceptual Illusions: Philosophical and Psychological Essays, edited by Clotilde, C., 207-24. Palgrave Macmillan.

Van Roojen, M., 2014. "Moral Intuitionism, Experiments and Skeptical Arguments." In Intuitions, edited by Booth, A., and Rowbottom, D., 148-64. Oxford University Press. 
Vance, J. 2014. "Emotion and the New Epistemic Challenge From Cognitive Penetrability.” Philosophical Studies 169 (2):257-283.

Vogel, J. 2008. “Epistemic Bootstrapping.” Journal of Philosophy 105 (9):518-539.

Werner, P. Forthcoming. "Moral Perception and the Contents of Experience." Journal of

Moral Philosophy, DOI: 10.1163/17455243-4681063

Wiggins, D. 1998. “A Sensible Subjectivism?” In Needs, Values, Truth: Essays in the Philosophy of Value, Oxford: Blackwell.

1 'Emotion' refers to conscious and occurrent emotions throughout. Note that I think that emotions can be unconscious and dispositional.

${ }^{2}$ In both sensory experience and emotion, at least some aspects of the phenomenology may be the (re)presentational vehicle.

${ }^{3}$ Döring identifies Perceptualism with EP, i.e., emotions are analogous to experiences in virtue of their normative properties. This complication shouldn't make a difference to my discussion - but the reader should note that, as I'm characterising things, the views are distinct.

${ }^{4}$ Oddie (2005) argues that desires play a similar epistemic role vis-à-vis judgments about goodness to that afforded to emotions by EPs. The reader is invited to consider how my arguments impact on Oddie's view.

${ }^{5}$ These points are raised by Tappolet (2000).

${ }^{6}$ See Pelser (2014) for the Unreliability Objection.

${ }^{7}$ This is indebted to remarks in Brady (2013); Deonna and Teroni (2012).

${ }^{8}$ To keep discussion tractable I set aside Prinz's (2004) view that emotions are affective perceptions of bodily change which double-up as indirect representations of values. The reader is invited to consider how my arguments bear on that view.

9 There are precedents for a multi-component view like Complex elsewhere in the philosophy of mind, e.g., Evaluativist views of painful pains (Bain, 2013) and some Perceptualist views of intuitions (Chudnoff, 2013). Note that Chudnoff allows that intuitions can be partly constituted by beliefs.

${ }^{10}$ Some proponents, e.g., Döring, talk of non-inferential rather than immediate justification. Others, e.g., Pelser, speak of basic justification. I assume the mainstream view that these are equivalent. See, e.g., Pryor (2005) and, Lyons (2009).

${ }^{11}$ Brady (2013) assumes Reliabilism.

${ }^{12}$ See also Dokic and Lemaire (2013) for discussion of the distinction between representation and presentation.

13 Reductive views also apparently require that our understanding of emotions doesn't make reference to evaluative properties. One might think that the conjunction of NS and Perceptualism renders the former view circular because values would appear on either side of the biconditional (recall that emotions represent evaluative properties according to Perceptualism). Two responses: one is to endorse a no-priority view of value and reasons for emotional responses. The other is to claim that emotions don't represent values but have NS content (I discuss this in $\S 4$ ).

${ }^{14}$ Perhaps it has an epistemic character. Note that this is distinct from Tappolet's view (2011) that we best understand fittingness non-normatively in terms of 'accuracy', e.g., $\mathrm{X}$ is dangerous iff fearful response to $\mathrm{X}$ is accurate.

${ }^{15}$ This argument is similar to that offered in favour of Buck-Passing Accounts of value to the effect that value properties, e.g., goodness, don't themselves provide reasons for actions or pro-attitudes over-and-above those provided by the (natural?) properties that constitute them. To count these as providing reasons would be to engage in double-counting. See, e.g., Scanlon (1998).

${ }^{16}$ Pelser (2014) gestures towards this.

${ }^{17}$ In Brady (2013) chapter 4, something like this objection is presented. This may be what was really intended in the first version.

${ }^{18}$ This requires that sensory experiences have high-level content, i.e., properties are represented in experience over-and-above 'low-level' properties of colours, shapes, etc.

${ }^{19}$ See Kauppinen (2013) for the view that moral intuitions are constituted by moral emotions. 
${ }^{20}$ But see Dokic and Lemaire (2013) who argue that the evaluative content of emotions is due to enrichment by “explicit and implicit beliefs, cognitive habits, past experience and associations” (243). I don’t have space to address this. However, note that there's a similarity to what Brady calls 'experience and reflection'.

${ }^{21}$ I'm setting aside 'experience and reflection'. Generally, it's unclear whether experience and reflection is really a source of justification that's epistemically independent of emotion.

${ }^{22}$ This is distinct from the claim that in making a judgment about a token case, one perhaps could - via one's understanding of moral concepts - come to justifiably believe something about that type of case.

${ }^{23}$ One can take my responses to the Superfluity Objections (and the Self-Justification Objection) as a partial response to Brady's (2013) claim that emotions are mere proxy justifications for evaluative judgments.

${ }^{24}$ Dokic and Lemaire (2013) complain that attributing NS content to emotions "rests on a wildly implausible description of our emotions.” (236)

${ }^{25}$ Things are complicated by the fact that there are several ways in which emotions might fit their objects, e.g., moral and prudential. Pinning down just what sense of fittingness, if any, is conveyed in emotion is therefore difficult. The best we can do is to consider a range of cases where it seems that prudential considerations aren't at stake, and which cross-cut the moral/non-moral divide. The cases I mention are presented in that spirit. 